\title{
Inpatient versus outpatient rehabilitation for multiple sclerosis patients: effects on disability and quality of life
}

\author{
Angelo Pappalardo ${ }^{1,2+}$, Emanuele D’Amico ${ }^{1 \dagger}$, Carmela Leone ${ }^{1}$, Silvia Messina ${ }^{1}$, Clara Chisari ${ }^{1}$, L. Rampello $^{1}$, \\ Lina Torre ${ }^{3}$ and Francesco Patti ${ }^{1^{*}}$
}

\begin{abstract}
Background: The most suitable setting of rehabilitation for Persons with Multiple Sclerosis (PwMS) has not been identified so far because there is a general lacking of controlled studies. Aim of this study was to evaluate the treatment efficacy in terms of functional independence between two different settings.

Methods: A randomized, wait-list controlled study was performed at the MS Center of the University of Catania, and Rehabilitation Center of the Hospital of Acireale, Italy. Inclusion criteria were: a) range of age 18-75, b) Expanded Disability Status Scale $\geq 4.0$ and $\leq 8.0$ c) self-reported worsening of standing or walking abilities in the last 6 months. The examining physician was blind to patient allocation program. The Functional Independence Measure (FIM), and the 36-Health Survey Questionnaire (SF-36) data were collected at T0 (baseline) and T1 (follow-up).

Results: One-hundred forty-six patients were randomly assigned to three groups. Forty-nine PWMS were allocated in the outpatient treatment group (Group A), 49 patients in the inpatients treatment group (Group B) and 48 patients in the control waiting list (Group C).

Both Group A and Group B showed a significant improvement in total FIM scores ( $p=0.03, p=0.008$; respectively) at T1 compared to T0. No difference was found between Group A and B with regard to the FIM scores in the intergroup analysis. Group A showed significant improvement at T1 compared to T0 in all sub-items of SF-36 $(p<0.05)$, contrary to Group B. A significant difference in total FIM score between the three groups was found $(p=0.0003)$. The pairwise comparisons showed a significant difference between Group A vs Group C ( $p=0.003)$ and Group B versus Group C $(p=0.001)$.
\end{abstract}

Conclusions: Inpatients and oupatients rehabilitation approaches both showed efficacy in improving total FIM score. Outpatient rehabilitation setting seems to be more effective in improving patients QoL.

Keywords: Multiple sclerosis, Neurorehabilitation, Outpatient, Inpatient, FIM, QoL

\section{Background}

Physical rehabilitation is generally accepted as useful for persons with MS (pwMS). A wide range of rehabilitation approaches is employed, ranging from more traditional strategies to newer techniques emphasizing the learning and practice of functional motor skills within a "taskspecific" context $[1,2]$. It is also important to identify

\footnotetext{
* Correspondence: patti@unict.it

${ }^{\dagger}$ Equal contributors

${ }^{1}$ GF Ingrassia Department, Neuroscience Section, First Neurology Clinic, Multiple Sclerosis Centre Sicilia Region, University Hospital Catania, Catania, Italy, Via S. Sofia 78, 90100 Catania, Italy

Full list of author information is available at the end of the article
}

the optimal approach for a given PwMS and to determine how long the effects last, estimating the costeffectiveness. Studies verifying the efficacy of physical rehabilitation require reliable, valid, and practical outcome measures. Functional independence and healthrelated quality of life (HRQoL) are among the outcome measures more investigated. Some studies showed as rehabilitation can improve the motor parameters of functional independence measures (FIM) in PwMS [3-7].

However, the clinical trials performed so far, focusing on different rehabilitation approaches have showed some limitations. Heterogeneity of MS phenotype, concomitant 
treatments with either disease modifying or symptomatic drugs, quantitative and qualitative disparity of rehabilitation treatment, lacking of appropriate and sensitive outcome instruments are all limits in performing a rehabilitative clinical trials. All of these factors can strongly influence the setting, the development and the outcomes of a rehabilitation program in clinical practice.

To date, four possible options of rehabilitation's setting are described in clinical practice: home-based therapy, outpatient ambulatory therapy, inpatient hospital-based therapy and outpatient hospital-based therapy $[3-5,8-20]$.

However, guidelines addressing the clinicians to the rational allocation of PwMS in a specific rehabilitative program are lacking.

Aim of our study is to investigate the treatment efficacy in terms of FIM scores between inpatient and outpatient neurorehabilitation programs. Furthermore, we evaluated the effects of two different settings of rehabilitation on quality of life.

\section{Methods}

A randomized, wait-list controlled study was performed at the MS Center of the University of Catania, Italy and, at the Rehabilitation Center of the S. Marta \& S. Venera Hospital in Acireale, Catania, Italy. The formal plan of the study was approved by the local Ethics Committee in September 2007. All enrolled PwMS signed a written informed consent.

A total of 260 pwMS, consecutively admitted to MS Center from 1st January to 30th June 2008, were screened for the inclusion and exclusion criteria. All the PwMS suffered by a clinically defined MS according to 2005 revisions to the McDonald diagnostic criteria [21]. The required inclusion criteria were: a) range of age between $18-75$, b) disability status assessed by Expanded Disability Status Scale (EDSS) [22] $\geq 4.0$ and $\leq 8.0, c)$ self-reported worsening of standing or walking abilities for at least 6 months.

Exclusion criteria were: a) PwMS with a diagnosis of MS less than six months; b) history of recent ( $<3$ months) disease relapse; c) recent ( $<6$ months) admission to MSspecific hospital-based rehabilitation; d) presence of cognitive deficits (Mini Mental State Examination-MMSE <24) [23]; presence of depressive symptoms (Beck Depression Inventory-BDI >11) [24]; e) severe heart or lung disease; drug or alcohol abuse; any other illness that could have excluded the participation in the study. PwMS were monitored along the study period for any neurological and other medical complications. Experiencing a relapse during the study period was considered criteria for dropping out.

Randomization was performed using a computer generated sequence at MS center in Catania. The randomization was stratified according to gender, age, EDSS score. The treating physician in charge of the rehabilitation project invited the PwMS to participate in the study and explained the rehabilitative intervention.

The examining physician, blind to patient allocation program, assessed each PwMS at baseline (T0) and at last day of rehabilitation period (T1). Both T0 and T1 were performed at the MS Center of the University of Catania. Both in-and-outpatient, just discharged from the rehabilitation hospital, went to MS Center to perform T1-evaluation; soon after they returned home. In Group C, T1-evaluation was carried out 40 days after T0.

EDSS, FIM [25] and 36-Health Survey Questionnaire (SF-36) [26] were administered as outcome measures.

The PwMS were randomly assigned to three different groups: Group A, outpatients rehabilitation treatment, Group B, inpatients rehabilitation treatment and Group $\mathrm{C}$, no rehabilitation treatment (PwMS in waiting list of rehabilitation treatment).

In Group A, rehabilitative treatment was performed once daily, six days per week, for five consecutive weeks. Overall, PwMs received 30 sessions of treatment. Every session lasted at least $60 \mathrm{~min}$, as described elsewhere $(4,12)$. PwMS reached the Rehabilitation Center by car or public transport.

In Group B rehabilitation treatment was performed twice-daily, for six days per week. The period of treatment was 35 days. Overall, PwMS received 60 sessions of treatment. Every session lasted at least $60 \mathrm{~min}$. Rehabilitation treatment for both groups was performed at the Rehabilitation Center of the S. Marta \& S. Venera Hospital in Acireale. Patients were not allowed to come back home on the day without rehabilitative treatment.

Group C included PwMS in a waiting list (between 4 and 6 months for being involved in an inpatient or an outpatient setting).

The rehabilitative team was composed by 13 rehabilitation therapists. All therapists were specialized in neurological rehabilitation and had 5 to 10 years of work experience.

The study ended in June 2009.

\section{Rehabilitation program}

The aim of rehabilitation program was to address motor, sensor, balance, strength, sphincter functions whether present; specific physiotherapy sessions, languages or swallowing or pelvic rehab were administered for at least 4 days a week; pelvic or speech one day a week; finally one day a week all patients were treated with a global therapy approach consisting of five sessions. The rehabilitative treatment was tailored to the specific individual needs and was planned on volitional tasks mainly 
focused on motor performances. We kept into account the assertion that potential changes are specific to a given task and not a general effect of any training $[27,28]$. PwMS were treated according to a protocol based on voluntary exercises for neuromuscular control, aimed to improve muscle strength of both upper and lower limbs, propioceptive sensibility, stability and coordination for balance. These exercises were mainly taskoriented and aimed to ameliorate the activities of daily living. More in details, we set up a protocol of treatment, which was identical in the two treated groups. In the first thirty minutes of each daily session, every PwMS was asked setting a table, screwing a cap on a bottle, sweeping a table, binding and untying some laces, and creating objects with clay. In the subsequent fifteen minutes, PwMS performed some non-task oriented exercises including: catching wooden cubes of different sizes, building geometric shapes with cubes and grabbing moving objects. In the last fifteen minutes of each session, all pwMS underwent a specific training of locomotion and exercises facilitating the elicitation of postural adjustments for static and dynamic balance. The examining physician avoided to discuss any issue related to the rehabilitative treatment setting.

\section{Primary outcome}

The primary outcome was to evaluate the difference in FIM score between $\mathrm{T} 0$ and $\mathrm{T} 1$ in groups $\mathrm{A}$ and $\mathrm{B}$. To detect a $20 \%$ difference between time-point, 146 PwMS entered this parallel-design study. The probability is 99 percent that the study will detect a treatment difference at a two-sided 0.05 significance level, if the true difference between treatments is 0.842 times the standard deviation.

\section{Statistical analysis}

PwMS was defined as a responder to rehabilitation treatment if she/he showed a $20 \%$ improvement in T1 total FIM score compared to T0.

Quantitative variables were described using mean and standard deviation, categorical variable were described by proportions. To assess the change in total FIM score, Motor FIM subitems score, Cognitive FIM subitems score between groups, we calculated the delta value by subtracting T0 pre-treatment score from T1 score.

Data were analyzed using STATA 10.0 software packages. A $p$ value $<0.05$ was considered as statistically significant. The difference between means and the difference between proportions was evaluated by the $t$-test and the Fisher exact test respectively. In case of not a normal distribution appropriate non-parametric tests were performed. ANOVA with a Bonferroni correction for multiple comparison was performed to assess the differences between groups. Mann-Whitney was performed to assess the difference between time-points.

\section{Results}

Out of the 260 screened PwMS, 114 were not enrolled, because 59 did not satisfy inclusion criteria, 40 refused to participate and 15 lived far away from the rehabilitation center (a long distance to the Rehabilitation Center was arbitrarily considered a disadvantage to be enrolled in the study). Thus, 146 PwMS were included and randomized using a computer generated sequence.

Forty-nine were allocated in the Rehabilitation Outpatients Treatment (Group A); 49 in the Rehabilitation Inpatient Treatment (Group B) and 48 in Control Waiting List (Group C). Baseline demographic and clinical characteristics of the 146 enrolled PwMS are summarized in Table 1. There were not significant differences among the three groups for all variables. All randomized PwMS completed the study and were analyzed. No drop-outs were observed for any of the three groups of the study.

Total FIM score improved in $22.6 \%$ of patient in group A and $14.6 \%$ in group B $(p=0.5)$. Motor FIM subitems improved in $32 \%$ of patients in group A and $21.4 \%$ in group B $(p=0.4)$ while cognitive FIM subitems showed no improvement in group A and an improvement in $3.5 \%$ of patients in group B.

\section{Intragroup analysis}

We found a significant difference in term of total FIM score between T0 and T1 in Group A ( $91 \pm 9.9$ vs 98.6 $\pm 15.2, p=0.03)$, in Group B $(89.4 \pm 20$ vs $98.3 \pm 17.3$, $p=0.008)$ and Motor FIM subitems score in Group A $(59 \pm 9.4$ vs $66 \pm 13.4, p=0.02)$ (Table 2). In Group C, was found no significant variation between $\mathrm{T} 0$ and T1in terms of total FIM scores and its subitems.

Variations of SF-36 domains are presented in Table 3. Significant differences were observed at $\mathrm{T} 1$ compared to

Table 1 Randomized patients' clinical and demographic characteristics

\begin{tabular}{|c|c|c|c|c|}
\hline & Group A & Group B & Group C & $p$ \\
\hline Number-N. of pts & 49 & 49 & 48 & \\
\hline N. Male (\%) & $18(37)$ & $17(35)$ & $18(37)$ & $\begin{array}{l}\text { No significant } \\
\text {-ns }\end{array}$ \\
\hline N. Women (\%) & $31(63)$ & $32(65)$ & $30(62)$ & ns \\
\hline $\begin{array}{l}\text { Age, mean } \pm \text { sd } \\
(\text { min-max })\end{array}$ & $\begin{array}{l}48.0 \pm 10.0 \\
(25-60)\end{array}$ & $\begin{array}{l}46.0 \pm 9.0 \\
(32-74)\end{array}$ & $\begin{array}{l}45.0 \pm 5.0 \\
(30-57)\end{array}$ & ns \\
\hline $\begin{array}{l}\text { Employed patients } \\
\text { N. (\%) }\end{array}$ & $13(26)$ & $8(16)$ & $14(29)$ & \\
\hline \multicolumn{5}{|l|}{ Disease course } \\
\hline $\begin{array}{l}\text { Secondary-Progressive } \\
\text { N. (\%) }\end{array}$ & $31(63)$ & $32(65)$ & $30(62)$ & ns \\
\hline $\begin{array}{l}\text { Primary-Progressive } \\
\text { N. (\%) }\end{array}$ & $18(37)$ & $17(35)$ & $18(37)$ & ns \\
\hline Mean \pm sd EDSS & $6.5 \pm 1.0$ & $6.5 \pm 1.1$ & $6.4 \pm 0.6$ & ns \\
\hline
\end{tabular}


Table 2 Comparison of FIM total score; motor and cognitive sub-items between T0 and T1 in three groups

\begin{tabular}{|c|c|c|c|c|c|c|c|c|c|}
\hline \multirow[b]{2}{*}{ Variables } & \multicolumn{3}{|l|}{ Group A } & \multicolumn{3}{|l|}{ Group B } & \multicolumn{3}{|l|}{ Group C } \\
\hline & $\begin{array}{l}\text { T0 } \\
\mathrm{m} \pm \mathrm{sd}\end{array}$ & $\begin{array}{l}\mathrm{T} 1 \\
\mathrm{~m} \pm \mathrm{sd}\end{array}$ & $p$ & $\begin{array}{l}\text { T0 } \\
\mathrm{m} \pm \mathrm{sd}\end{array}$ & $\begin{array}{l}\mathrm{T} 1 \\
\mathrm{~m} \pm \mathrm{sd}\end{array}$ & $p$ & $\begin{array}{l}\text { T0 } \\
\mathrm{m} \pm \mathrm{sd}\end{array}$ & $\begin{array}{l}\mathrm{T1} \\
\mathrm{m} \pm \mathrm{sd}\end{array}$ & $p$ \\
\hline Total FIM & $91 \pm 9.9$ & $98.6 \pm 15.2$ & 0.03 & $89.4 \pm 20$ & $98.3 \pm 17.3$ & 0.008 & $89.5 \pm 15.9$ & $89.3 \pm 15.9$ & ns \\
\hline Motor subtotal score & $59 \pm 9.4$ & $66 \pm 13.4$ & 0.02 & $59 \pm 18.5$ & $67 \pm 16.1$ & 0.09 & $58 \pm 12.8$ & $58 \pm 12.9$ & ns \\
\hline Cognitive subtotal score & $32 \pm 2.8$ & $32 \pm 2.4$ & ns & $31 \pm 3.8$ & $32 \pm 3.4$ & ns & $31.5 \pm 4.5$ & $31 \pm 4.5$ & ns \\
\hline
\end{tabular}

Mann-Whitney test was performed between T0 and T1

T0 only in Group A. In particular, the most significant change was found in physical role functioning $(31.8 \pm$ 34.8 vs $55 \pm 42.9, p<0.0001)$, vitality $(46.7 \pm 16.8$ vs $58.4 \pm 15.1, p<0.0001)$, social role functioning (56.6 \pm 22.1 vs $76.7 \pm 18.7, p<0.0001)$ and mental health $(54.4 \pm$ 18.5 vs $64.8 \pm 17.3, p<0.0001)$.

\section{Intergroup analysis}

Delta values of total FIM score, motor FIM subitems score and cognitive FIM subitems score were compared between the three groups (group A, group B, group C). A significant difference in total FIM score between the three groups was found $(p=0.0003)$. When the pairwise comparisons were investigated, we found a significant difference between Group A vs Group C $(p=0.003)$ and Group B versus Group C $(p=0.001)$. Motor FIM subitems score was significantly different between groups $(p=0.0001)$. The pairwise comparison showed a significant difference between Group A versus Group C $(p<$ $0.001)$ and in Group B versus Group C $(p<0.001)$. No significant differences in cognitive FIM subitems scores were observed between the three groups (see Table 4).

\section{Discussion}

The results of this randomized study showed significant and clinically meaningful changes in term of impact on the functional independence inpatient and outpatient rehabilitation in comparison with no intervention. In particular, the subcategories of motor FIM demonstrated higher improvement compared to the other subcategories, showing as PwMS can gain benefits in their daily-living activities as well as in their mobility. The improvement of motor FIM was found in 32 and $21.4 \%$ of patients respectively in Group A and B. These percentages, although not high, were obtained as we defined a patient as responder to rehabilitation whether he/she showed a $20 \%$ improvement in T1 compared to T0. We choose a low cut-off in order to more spot the potential of neurorehabilitation in PwMS.

The efficacy of rehabilitation in PwMS was just described elsewhere [3, 4, 8-20, 29-34].

A Cochrane review including 260 patients showed strong evidence for exercise therapy compared to no exercise therapy in terms of muscle power function, exercise tolerance functions and mobility-related activities [30]. A recent systematic review including 54 studies, found strong evidence that exercise performed two times per week increases aerobic capacity and muscular strength, whereas the evidence was not consistent regarding the effects of exercise training on mobility, fatigue, and health-related quality of life [29].

Over the past 20 years, numerous studies have been published that for the design, number of enrolled patients, outcome measures, rehabilitative strategy and setting; that is studies performed in inpatient, outpatient and home-based rehabilitation. Inpatient setting was

Table 3 SF-36 domains. Comparison among the three groups at T0 and T1

\begin{tabular}{|c|c|c|c|c|c|c|c|c|c|}
\hline \multirow[b]{2}{*}{ Domains } & \multicolumn{3}{|l|}{ Group A } & \multicolumn{3}{|l|}{ Group B } & \multicolumn{3}{|l|}{ Group C } \\
\hline & $\begin{array}{l}\text { Baseline } \\
\mathrm{m} \pm \mathrm{sd}\end{array}$ & $\begin{array}{l}\mathrm{T}_{1} \\
\mathrm{~m} \pm \mathrm{sd}\end{array}$ & $p$ & $\begin{array}{l}\text { Baseline } \\
\mathrm{m} \pm \mathrm{sd}\end{array}$ & $\begin{array}{l}\mathrm{T}_{1} \\
\mathrm{~m} \pm \mathrm{sd}\end{array}$ & $p$ & $\begin{array}{l}\text { Baseline } \\
\mathrm{m} \pm \mathrm{sd}\end{array}$ & $\begin{array}{l}\mathrm{T}_{1} \\
\mathrm{~m} \pm \mathrm{sd}\end{array}$ & $p$ \\
\hline Physical function & $31.2 \pm 20.7$ & $37.8 \pm 28$ & $p<0.05$ & $25.8 \pm 19.1$ & $26.6 \pm 20.2$ & ns & $23.5 \pm 15.5$ & $24.4 \pm 17.7$ & ns \\
\hline Physical role functioning & $31.8 \pm 34.8$ & $55 \pm 42.9$ & $p<0.0001$ & $30 \pm 22$ & $31.4 \pm 18.5$ & ns & $31.2 \pm 37$ & $28.4 \pm 35.3$ & ns \\
\hline Bodily pain & $52.7 \pm 25.8$ & $67.2 \pm 23.8$ & $p<0.001$ & $62.9 \pm 28.2$ & $67.5 \pm 26.9$ & ns & $64.4 \pm 28.6$ & $63.1 \pm 28.4$ & ns \\
\hline General health perceptions & $48.8 \pm 19.6$ & $52.5 \pm 19.2$ & $p<0.001$ & $44.6 \pm 17.8$ & $49.5 \pm 20.5$ & ns & $51 \pm 20.2$ & $50.2 \pm 19.5$ & ns \\
\hline Vitality & $46.7 \pm 16.8$ & $58.4 \pm 15.1$ & $p<0.0001$ & $41.2 \pm 16.7$ & $43 \pm 18.8$ & ns & $48.5 \pm 20.1$ & $46.2 \pm 18.3$ & ns \\
\hline Social role functioning & $56.6 \pm 22.1$ & $76.7 \pm 18.7$ & $p<0.0001$ & $62.9 \pm 22.8$ & $64 \pm 26.2$ & ns & $60.8 \pm 25.8$ & $59 \pm 25$ & ns \\
\hline Emotional role functioning & $60.8 \pm 39.6$ & $73.1 \pm 34.6$ & $p<0.05$ & $48.8 \pm 41.1$ & $49.6 \pm 38.3$ & ns & $45.3 \pm 43.6$ & $44.3 \pm 43.5$ & ns \\
\hline Mental health & $54.4 \pm 18.5$ & $64.8 \pm 17.3$ & $p<0.0001$ & $62 \pm 25.5$ & $67 \pm 23.5$ & ns & $59 \pm 26.1$ & $56.9 \pm 24.9$ & ns \\
\hline
\end{tabular}

$p<0.05$ - Wilcoxon signed rank for Group A versus both Group B and Group C 
Table 4 Delta value between three groups

\begin{tabular}{|c|c|c|c|c|}
\hline Variables & Group A & Group B & Group C & $p$ \\
\hline Total FIM & $8 \pm 12$ & $8,9 \pm 9,7$ & $-0,2 \pm 0,6$ & $0.0003^{*}$ \\
\hline Motor subtotal score & $8 \pm 9,5$ & $8 \pm 9,2$ & $0 \pm 0,7$ & $0.0001^{* *}$ \\
\hline Cognitive subtotal score & $0 \pm 3,1$ & $0,7 \pm 1,3$ & 0 & 0.3053 \\
\hline
\end{tabular}

associated with a significant improvement in functional impairment [15], disability [10, 32], functional independence [3] and HRQoL [3, 10, 32]. Trials conducted in outpatient setting demonstrated effectiveness of rehabilitation in improvement of muscular strength (9), walking capacity [34], functional independence [4], HRQol [9, 11, 12, 34]. Home-based rehabilitation showed significant improvement in HRQoL [13, 16], balance [17, 19], leg extensor power [14], gait parameters [20], fatigue [10].

Very recently, an exercise-based patient education program conducted at home or at outpatient set, demonstrated improvements in PwMS' mobility, gait ability, endurance, fatigue, and health-related quality of life after completing the 12-week intervention [31].

As exposed in the introduction, we searched to address an unresolved question in MS clinical practice: what is the most suitable setting for PwMS? This issue is becoming crucial, considering that the majority of MS patients required rehabilitation treatment [35] and that leads to increasing health costs [36]. To the best of our knowledge, only few studies were designed considering a comparison between two different settings of rehabilitation (outpatient versus inpatient). Francabandera et al. [8] reported that inpatient rehabilitation resulted in small but significant improvements in ambulatory status and level of independence in self-care as compared with outpatient treatment. But that study enrolled PwMS with a more severe disability (EDSS score 6.0 - 9.0) than ours and the outpatient group received physical and occupational therapy not only i a clinic but also at home; therefore a comparison with our work is difficult to perform.

In a more recent randomized study [5], both in-and -outpatient PwMS showed statistically significant improvement in FIM total score and in the FIM motor domains compared to controls; whereby the rehabilitation programme for PwMS determined important reduction in disability with a large treatment effect sizes for a number of FIM domains. In that study, unlike ours, the authors also enrolled PwMS affected by the Relapsing-Remitting phenotype; beside, they did not separately provide the data of the two setting of rehabilitation, as the objectives of that study were different from those of our study.
Traditionally, rehabilitation has been targeted at maintaining and preserving patient's personal and social activities. The findings of our study, as well as those of others studies, advice us that the goals of neurorehabilitation should be renewed, targeting to the improvement of the residual capacities and so, enhancing the functional independence. To this aim, we believe that active rehabilitation, based on voluntary task-oriented exercises, could determine beneficial effects in terms of functional independence. In agreement with this assertion, Bonzano et al. demonstrated that rehabilitation treatment based on voluntary movements may contribute to preserve the white matter integrity in the corpus callosum and corticospinal tracts and to maintain the coordination ability; such benefits were not observed in control group [27]. These findings confirms the hypothesis that the sensorimotor deficits observed in PwMS over the disease course could be mainly due to the progression of white matter damage and that neurorehabilitation may attenuate this neurodegenerative process [37, 38].

In our study, just Group A showed a significant improvement social and psychological parameters in SF-36. In Group B, we found a slight but not statistically significant improvement in all domains of SF-36. Some years ago, other authors were reached to the same finding; inpatient treated group improved in functional impairment but not in HRQoL [15]. Therefore, the lack of efficacy on HRQoL in Group B might be related to the hospitalization, which could have determined a greater psychological stressful effect and we sought to screen that in the future. To the outpatients were offered the possibility to came back home after every treatment session, and therefore, they could continue their jobs and their social activities. That support the evidence of the most meaningful benefit in QoL domain social role functioning for these PwMS.

These findings may draw the conclusion that a different setting for rehabilitation treatment should be chosen taking into account many personal needs and desires of each patient. A physician dealing with a rehabilitative treatment should bear in mind the emotional aspects in PwMS to come back home at the end of each daily session. A recent study showed that PwMS had less functional improvement than other populations using the inpatient rehabilitation setting and the higher rates of depression was found within the MS population [39]. This finding must be an important consideration for rehabilitation service needs in PwMS.

The willingness and the economic possibilities of the patients to get the rehabilitative center every day have to be considered as well their wishes of improvement.

However, which is the real impact of the hospitalization on the previous habitual activities of the patient's daily 
life? How could the hospitalization impact patient's social and psychological profile?

Nowadays it is very important the economic costs and relative cost-effectiveness of the different rehabilitative settings [36]. There is no doubt that outpatient rehabilitation is less expensive than the inpatient rehabilitation program, independently from the comparable effectiveness. At the same time, outpatient rehabilitation seems to be more burdensome for patients in terms of economic resources and familiar commitment (travel cost, caregiver time management, etc.).

We are aware about the limitations of our study. A percentage of about $45 \%$ of PWMS were nor enrolled and only patients with an EDSS $\geq 4.0$ and $\leq 8.0$ were recruited. That cannot generalize our results to a global MS population. However, the three groups had comparable baseline characteristics and adequate cognitive performing that allowed to reduce a major source of bias. Moreover, we did not perform follow-up assessment, but we aimed to set another study to ride over these limitations and to evaluate the eventual carry-on effects of both rehabilitation settings.

Despite the above limitations, we found that both rehabilitative treatment settings, inpatient and outpatient, are equally effective in diminishing the disability in PwMs. Interestingly, only the outpatient treatment was found to be effective in improving the HRQoL.

\section{Conclusions}

In conclusion, we believe that outpatient setting is usually well accepted by PwMS with minimal impact on patients habitual familiar and social life. However it should be underlined that inpatient setting could be more suitable for both patients with a more severe disability that have difficulties in terms of reaching the rehabilitative center and for those preferring to be treated without involvement of relatives or caregivers. More studies needed.

\section{Competing interests}

Dr. Patti has served on the scientific advisory board for Teva, Biogen-Idec, Bayer-Schering, Novartis and has received honoraria as a speaker for Teva, Biogen, Merck-Serono, Bayer-Schering, Genzyme/Sanofi, Novartis. Dr. D'Amico, Dr. Messina, Dr. Pappalardo, Dr. Rampello, Lina Torre have nothing to disclose.

\section{Authors' contributions}

AP carried out the study, participated in drafting the manuscript. ED carried out the study, participated in drafting the manuscript. SM carried out the study, participated in drafting the manuscript participated in the sequence alignment. $C L$ carried out the study, participated in drafting the manuscript. CC carried out the study, participated in drafting the manuscript. LT carried out the study. FP carried out the study, participated in drafting the manuscript, giving the final approval. All authors read and approved the final manuscript.

\section{Acknowledgments}

The authors would like to thank for the precious collaboration the physiatrist Laura Longo and Giuseppe Sicuso and the physioterapists Barchitta Rocco, Scuderi Letizia, La Spina Concetta, Buzzone Concetta, Corallo Serena, De Carlo Davide, Vinci Ornella, D’Urso Patrizia, Blanco Mario, Cuddè Agrippina, Casablanca Paolo, Pennisi Stefania, Pennisi Angela, Alfio Nicolosi, Biagio Papotto, Mario Vincenzino.

\section{Author details}

${ }^{1}$ GF Ingrassia Department, Neuroscience Section, First Neurology Clinic, Multiple Sclerosis Centre Sicilia Region, University Hospital Catania, Catania, Italy, Via S. Sofia 78, 90100 Catania, Italy. ${ }^{2}$ Department of Rehabilitation, S. Marta \& S.Venera Hospital, ASP Catania, Acireale, Catania, Italy. ${ }^{3}$ Rehabilitation Unit, Opera Diocesana Assistenza, Catania, Italy.

Received: 24 June 2015 Accepted: 17 February 2016

Published online: 01 April 2016

\section{References}

1. Beer $\mathrm{S}, \mathrm{Khan} F$, Kesselring J. Rehabilitation interventions in multiple sclerosis: an overview. J Neurol. 2012;259:1994-2008.

2. Morgen K, Kadom N, Sawaki L, et al. Training-dependent plasticity in patients with multiple sclerosis. Brain. 2004;127:2506-17.

3. Solari A, Filippini G, Gasco P, et al. Physical rehabilitation has a positive effect on disability in multiple sclerosis patients. Neurology. 1999;52(1):57-62.

4. Patti F, Ciancio MR, Cacopardo M, et al. Effects of a short outpatient rehabilitation treatment on disability of multiple sclerosis patients-a randomised controlled trial. J Neurol. 2003;250(7):861-6.

5. Khan F, Pallant JF, Brand C, et al. Effectiveness of rehabilitation intervention in persons with multiple sclerosis: a randomised controlled trial. J Neurol Neurosurg Psychiatry. 2008;79(11):1230-5.

6. Schwartz I, Sajin A, Moreh E, et al. Robot-assisted gait training in multiple sclerosis patients: a randomized trial. Mult Scler. 2012;18(6):881-90.

7. Khan F, Pallant JF, Zhang $N$, et al. Clinical practice improvement approach in multiple sclerosis rehabilitation: a pilot study. Int J Rehabil Res. 2010;33(3):238-47.

8. Francabandera FL, Holland NJ, Wiesel-Levison P, et al. Multiple Sclerosis Rehabilitation: Inpatient vs. Outpatient Rehabil Nurs. 1988;13:251-3.

9. Petajan JH, Gappmaier E, White AT, et al. Impact of aerobic training on fitness and quality of life in multiple sclerosis. Ann Neurol. 1996;39(4):432-41.

10. Freeman JA, Langdon DW, Hobart JC, et al. The impact of inpatient rehabilitation on progressive multiple sclerosis. Ann Neurol. 1997;42(2):236-44.

11. Di Fabio RP, Choi T, Soderberg J, et al. Health-related quality of life for patients with progressive multiple sclerosis: influence of rehabilitation. Phys Ther. 1997;77(12):1704-16.

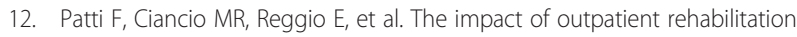
on quality of life in multiple sclerosis. J Neurol. 2002;249(8):1027-33.

13. Pozzilli C, Brunetti M, Amicosante AM, et al. Home based management in multiple sclerosis: results of a randomised controlled trial. J Neurol Neurosurg Psychiatry. 2002;73(3):250-5.

14. DeBolt LS, McCubbin JA. The effects of home-based resistance exercise on balance, power, and mobility in adults with multiple sclerosis. Arch Phys Med Rehabil. 2004;85(2):290-7.

15. Romberg A, Virtanen A, Ruutiainen J, et al. Long-term exercise improves functional impairment but not quality of life in multiple sclerosis. J Neurol. 2005;252(7):839-45.

16. McCullagh R, Fitzgerald AP, Murphy RP, et al. Long-term benefits of exercising on quality of life and fatigue in multiple sclerosis patients with mild disability: a pilot study. Clin Rehabil. 2008;22(3):206-14.

17. Finkelstein J, Lapshin O, Castro H, et al. Home-based physical telerehabilitation in patients with multiple sclerosis: a pilot study. Rehabil Res Dev. 2008;45(9):1361-73.

18. Vikman T, Fielding $P$, Lindmark $B$, et al. Effects of inpatient rehabilitation in multiple sclerosis patients with moderate disability. Adv Physiother. 2008; 10(2):58-65.

19. Prosperini L, Fortuna D, Giannì C, et al. Home-based balance training using the Wii balance board: a randomized, crossover pilot study in multiple sclerosis. Neurorehabil Neural Repair. 2013;27(6):516-25.

20. Conklyn D, Stough D, Novak EA, et al. Home-based walking program using rhythmic auditory stimulation improves gait performance in patients with multiple sclerosis: a pilot study. Neurorehabil Neural Repair. 2010;24(9):835-42.

21. Polmann $\mathrm{CH}$, Reingold SC, Edan $\mathrm{G}$, et al. Diagnostic criteria for multiple sclerosis: 2005 revisions to the "McDonald Criteria". Ann Neurol. 2005;58(6):840-6.

22. Kurtzke JF. Rating neurologic impairment in multiple sclerosis: an expanded disability status scale (EDSS). Neurology. 1983;33(11):1444-52.

23. Beatty WW, Goodkin DE. Screening for cognitive impairment in multiple sclerosis. An evaluation of the Mini-Mental State Examination. Arch Neurol. 1990;47:297-301.

24. Sullivan MJ, Weinshenker B, Mikail S, et al. Screening for major depression in the early stages of multiple sclerosis. Can J Neurol Sci. 1995;22:228-31. 
25. Keith RA, Granger CV, Hamilton BB, et al. The functional independence measure: a new tool for rehabilitation. Adv Clin Rehabil. 1987;1:6-18,

26. Garratt AM, Ruta DA, Abdalla MI, et al. The SF36 health survey questionnaire: an outcome measure suitable for routine use within the NHS? BMJ. 1993;306(6890):1440-4.

27. Bonzano L, Tacchino A, Brichetto G, et al. Upper limb motor rehabilitation impacts white matter microstructure in multiple sclerosis. Neuroimage. 2014;90:107-16.

28. Thomas C, Baker $\mathrm{Cl}$. Teaching an adult brain new tricks: a critical review of evidence for training-dependent structural plasticity in humans. Neuroimage. 2013;73:225-36.

29. Latimer-Cheung AE, Pilutti $L A$, Hicks $A L$, et al. The effects of exercise training on fitness, mobility, fatigue, and health related quality of life among adults with multiple sclerosis: a systematic review to inform guideline development. Arch Phys Med Rehabil. 2013:94(9):1800-28.

30. Rietberg MB, Brooks D, Uitdehaag BM, Kwakkel G. Exercise therapy for multiple sclerosis. Cochrane Database Syst Rev. 2005;1, CD003980.

31. Kersten S, Mahli M, Drosselmeyer J et al. A Pilot Study of an Exercise-Based Patient Education Program in People with Multiple Sclerosis. Mult Scler Int 2014;:Epub 2014 Dec 21.

32. Gaber TA, Oo WW, Gautam V, et al. Outcomes of inpatient rehabilitation of patients with multiple sclerosis. NeuroRehabilitation. 2012;30(2):97-100.

33. Romberg A, Virtanen A, Ruutiainen J, et al. Effects of a 6-month exercise program on patients with multiple sclerosis: a randomized study. Neurology. 2004;63(11):2034-8.

34. Rampello A, Franceschini M, Piepoli M, et al. Effect of aerobic training on walking capacity and maximal exercise tolerance in patients with multiple sclerosis: a randomized crossover controlled study. Phys Ther. 2007;87(5):545-55.

35. Khan F, Turner-Stokes L, Ng L, Kilpatrick T. Multidisciplinary rehabilitation for adults with multiple sclerosis. Cochrane Database Syst Rev. 2007;2, CD006036. Review.

36. Patti F, Amato MP, Trojano M, et al. Multiple sclerosis in Italy: cost-of-illness study. Neurol Sci. 2011;32(5):787-94.

37. Ge Y, Law M, Grossman Rl. Applications of diffusion tensor MR imaging in multiple sclerosis. Ann N Y Acad Sci. 2005;1064:202-19.

38. Evangelou N, Esiri MM, Smith S, et al. Auantitative pathological evidence for axonal loss in normal appearing white matter in multiple sclerosis. Ann Neurol. 2000;47:391-5.

39. Morley MA, Coots LA, Forgues AL, et al. Inpatient rehabilitation utilization for Medicare beneficiaries with multiple sclerosis. Arch Phys Med Rehabil. 2012;93(8):1377-83.

\section{Submit your next manuscript to BioMed Central and we will help you at every step:}

- We accept pre-submission inquiries

- Our selector tool helps you to find the most relevant journal

- We provide round the clock customer support

- Convenient online submission

- Thorough peer review

- Inclusion in PubMed and all major indexing services

- Maximum visibility for your research

Submit your manuscript at www biomedcentral.com/submit

) Biomed Central 